\title{
Multifaceted Phytogenic Silver Nanoparticles by a Rare Insectivorous Plant Drosera Spatulata Labill Var.bakoensis and its Enhanced Antioxidant, Antibacterial, Antifungal and in Vitro Cytotoxic Studies
}

\section{Susmila Aparna Gaddam}

Sri Venkateswara University

Venkata Subbaiah Kotakadi

Sri Venkateswara University

Gunasekhar. Kalavakunta

Dravidian University

Josthna Penchalaneni

Sri Padmavathi Mahila ViswaVidyalayam SPMVV (Women's University)

Varadarajulu Naidu Challagundla

Dravidian University

Sai Gopal DVR

Sri Venkateswara University

Visweswara Rao Pasupuleti ( $\triangle$ pvrao@ums.edu.my)

Universiti Malaysia Sabah

\section{Research Article}

Keywords: Drosera spatulata Labill var. bakoensis, Green synthesis, Spectral characterization, antimicrobial activity, in vitro cytotoxic studies

Posted Date: July 8th, 2021

DOl: https://doi.org/10.21203/rs.3.rs-551191/v1

License: (c) (1) This work is licensed under a Creative Commons Attribution 4.0 International License. Read Full License 


\section{Abstract}

The current investigation highlights the green synthesis of silver nanoparticles (AgNPs) by the insectivorous plant Drosera spatulata Labill var.bakoensis, which is the first of its kind. The biosynthesized nanoparticles revealed a UV visible surface plasmon resonance (SPR) band at $427 \mathrm{~nm}$. The natural phytoconstituents which reduce the monovalent silver were identified by FTIR. The particle size of the Ds-AgNPs was detected by the Nanoparticle size analyzer confirms that the average size of nanoparticles was around $23 \pm 2 \mathrm{~nm}$. Ds-AgNPs exhibit high stability because of their high negative zeta potential $(-34.1 \mathrm{mV})$. AFM studies also revealed that the Ds-AgNPs were spherical in shape and average size ranges from 10 to $20 \pm 5 \mathrm{~nm}$. TEM analysis also revealed that the average size of Ds-AgNPs was also around $21 \pm 4 \mathrm{~nm}$ and the shape is roughly spherical and well dispersed. The crystal nature of DsAgNPs was detected as a face-centered cube by the XRD analysis. Furthermore, studies on antibacterial and antifungal activities manifested outstanding antimicrobial activities of Ds-AgNPs compared with standard antibiotic Amoxyclav. In addition, demonstration of superior free radical scavenging efficacy coupled with potential in vitro cytotoxic significance on Human colon cancer cell lines (HT-29) suggests that the Ds-AgNPs attain excellent multifunctional therapeutic applications.

\section{Introduction}

Presently, many researchers in the life science and biomedical field are working with scientists in material sciences to discover the various opportunities to detect the use of nanomaterials as innovative tools for cancer therapy. Green synthesized silver nanoparticles (AgNPs) have great prospects in cancer theranostics, such as nanoprobes for imaging, drug delivery, suppression of tumor growth and angiogenesis [1-3]. So, green synthesis of AgNPs is presently a very much attentive research field due to its easy, fast, and eco-friendly method without involving the utilization of organic solvents and perilous chemicals [4] and outlay to be efficient when compared with chemical and physical methods [5]. In addition, the plant based green synthesis is the finest candidate for wide-ranging fabrication of nanoparticles with controlled shape and size, however green synthesized nanoparticles comprise and detected to be irregular in size and shape in majority of the cases [6-7]. The bioactive phyto-constituents like polyphenols and other bio-constituents like flavinoids, tannins, alkaloids, saponins and glycosides, found in various parts of plants leaves, fruits, seeds, stem, bark and roots, are extensively used for biosynthesis of metal nanoparticles, which actively participate in reduction and stability of nanoparticles. The earlier reports from our studies also revealed that synthesized silver nanoparticles at room temperature are spherical and polydispered in nature, but anomalous in size and shape ranging between 20-80 nm [ 8-13]. There are several studies that have reported that plant bioactive compounds exert anticancer activity against various cancer cell lines. By adding up, plant polyphenols and anticancer molecules present in them can show the new ways for the progress of novel strategies for the treatment of various cancers due to their synergistic effect [14-15].

Drosera sp, commonly known as Sundews, was found to be an important medicinal herb since 12th century. It has been widely used and recommended by herbalists to cure various ailments like asthma, 
bronchitis, bronchial cramps, dry coughs whooping cough [16] and also exhibits anti-tussive properties [17]. It is also used as an natural aphrodisiac and to maintain the heart strength [18]. In addition, it is used in treating lung infections and stomach ulcer. Drosera sp is carnivorous in nature and the beauty of the plants is due to glossy traps, as a result they have turn out to be much loved ornamental plants [19]. Most popular Drosera spieces consist of $D$. aliciae, D. capensis and D. spatulata [20] next to Venus fly traps.

In recent times scientists are very much interested in checking the elastic properties of the mucilage produced by Drosera species like $D$. binata, $D$. capensis, and $D$. spatulata, which is an exceptionally smart idea for biomaterial research on synthesis of nanofibers and nanoparticles [21]. They have observed various sizes nanofibers and nanoparticles networks within the mucilage of these plants, which were confirmed by different spectroscopic techniques like Transmission electron microscopy (TEM) and Atomic force microscopy (AFM). The Energy-dispersive X-ray spectroscopy (EDAX) analysis revealed key biological salts like calcium, magnesium and chlorine [21]. The scientists detected a wide range of applications from the Drosera mucin or mucilage, which includes wound healing properties, tissue engineering and regenerative medicine. The mucilage of Drosera species is readily available source of biomaterial due its stretching property which can stretch million times then its original size. [21]. Sundews also contains several potential biologically active chemical compounds like flavoniods They also contain additional important phyto-constituents like carotenoids and various plant acids, resins, tannins and very important vitamin like ascorbic acid (vitamin C) [22-25].

The present work is primarily focused on the green synthesis of AgNPs using insectivorous plant extract of Drosera spatulata Labill var. bakoensis, which acts both as a reducing and stabilizing agent. The synthesized green Ds-AgNPs were used for subsequent spectral characterization using UV-vis, FTIR, XRD, TEM, EDAX and AFM. They were further used to explore the antioxidant, antimicrobial studies, and anticancer activities against human colon cancer cells to detect their potential therapeutic applications in different areas of biomedical sciences. The present work is represented in a schematic diagram (S1)

\section{Materials And Methods}

\subsection{Collection of Plant material and Preparation of the Extract}

Drosera spatulata Labill var. bakoensis A.Fleischm.\&Chi C.Lee plants (Fig.1A) were collected from the nitrogen deficient lands located at Thottambedu, Srikalahasti, Chittor district, Andhra Pradesh. (12 ${ }^{\circ} 37^{\prime}$ $14^{\circ} 8^{\prime}$ north latitudes and $78^{\circ} 3^{\prime}-79^{\circ} 55^{\prime}$ east longitudes) shown in Google map below. The identified plant was confirmed and authenticated [Herbarium No.NN2120/PURSESVU/2021] by Dr. N. Nagaraju, Associate Professor and Head Retd, Department of Botany, Sri Venkateswara Arts and Science College, Tirupati, Andhra Pradesh and voucher specimen was stored in Sri Venkateswara University, Tirupati. The plant collection and studies were according to the proper guidelines. The permission from the landowner has been obtained for the plant collection. The plant height was $2 \mathrm{~cm}$, the root depth was $0.50 \mathrm{~cm}$ and it was highly associated with soil particles while the plant flowered part diameter measured was $1.8 \mathrm{~cm}$. 
Wild Drosera spatulata Labill var. bakoensis plants were picked from field directly, thoroughly washed with distilled water until the roots were completely dissociated from the soil particles. Then these plants were dried in the shade at room temperature for 6 to 9 days and the dried plant material is kept in the hot air oven at $40^{\circ} \mathrm{C}$ temperature for overnight to remove any moisture left in the sample. The dried plant samples were ground into fine powder which was brownish in color and was used to carry out further studies.

\subsection{Green synthesis of silver nanoparticles}

The Drosera spatulata Labill var. bakoensis plants extract was prepared by taking $5 \mathrm{~g}$ of fine plant powder with $250 \mathrm{ml}$ of Milli Q water in a sterile $500 \mathrm{ml}$ conical flask and steadily mixed the mixture solution and kept in water bath at $60^{\circ} \mathrm{C}$ for 30 minutes, soon after than 30 minutes the prepared extract e was filtered through sterile muslin cloth followed by whatmann no. 1 filter paper. The filtrate solution was used to carry out the green synthesis of silver nanoparticles. $5 \mathrm{ml}$ of plant extract was diluted to $20 \mathrm{ml}$ with sterile Milli $Q$ water and then added $50 \mathrm{ml}$ of $0.002 \mathrm{M} \mathrm{AgNO}_{3}$ solution. The reaction mixture was left at room temperature and observe for color change of the solution, after few minutes the color changed to pale brown and subsequently to dark brown color within 10 minutes (Fig.1B.(a)(b). The color change of the reaction solution is due to the reduction of $\mathrm{AgNO}_{3}$ to silver ions. In the current study, the AgNPs have been biosynthesized by using whole plant extract of Drosera spatulata Labill var. bakoensis without any toxic chemicals. Hence these method is an environmentally safe "Green method"; hence the biosynthesized nanoparticles can be referred as Ds-AgNPs.

\subsection{Purification of biosynthesized Silver nanoparticles or Green Ds-AgNPs}

The purification Ds-AgNPs was carried out with modified procedure of Sucharitha et al (2018) [40]. The biosynthesized Ds-AgNPs solution containing silver nanoparticles were centrifuged at 15,000 rpm for 30 minutes to obtain the pure Ds-AgNPs pellet. The Ds-AgNPs pellets were re-dispersed in $15 \mathrm{ml}$ of sterile Milli Q water to get rid of unbound plant extract residues and biological molecules. The process of centrifugation and re-dispersion of Ds-AgNPs in sterile Milli Q water was repeated thrice to obtain pure green Ds-AgNPs. The purified green Ds-AgNPs pellets were used for consecutive studies like FTIR, EDX, XRD and other advanced spectroscopic methods like TEM and AFM.

\subsection{Spectral Characterization of Ds-AgNPs}

The biosynthesized Ds-AgNPs by the total plant extract of Drosera spatulata Labill var. bakoensis was analyzed using Nanodrop 8000 (UV-visible spectrophotometer, Thermo Scientific). The optical absorbance of the Ds-AgNPs was recorded at $220 \mathrm{~nm}-750 \mathrm{~nm}$ wavelength range from time to time 
sampling $1 \mu \mathrm{l}$ of sample and the reading were carried out at room temperature with $1 \mathrm{~nm}$ resolution. The Fourier transformed infrared (FTIR) spectrum analysis was carried out for biosynthesized Ds-AgNPs using Alpha T model, FTIR spectrophotometer, Bruker Company, to reveal the potential bioactive components of plant extract of Drosera spatulata Labill var. bakoensis responsible for the bio-reduction and stabilization of Ds-AgNPs. The particle size and zeta potential of the biosynthesized nanoparticles were determined by using Dynamic light scattering technique on Nanopartica analyzer SZ-100, Horiba scientific, Japan. The size, exterior surface morphology and topology of the green synthesized Ds-AgNPs were analyzed using Atomic Force Microscope (AFM-Solver Next, NT-MDT, Russia), by coating a thin film of Ds-AgNPs on sterile glass piece and air-dried completely prior to analysis. Transmission electron microscopy (TEM) analysis was carried out to identify the exact size and morphology of the synthesized Ds-AgNPs. The sample for TEM analysis was prepared by placing a drop of the purified Ds-AgNPs solution on a carbon-coated copper grids and allowed to dry completely and TEM analysis was carried out using FEI Tecnai F12 (Philips Optics Ltd, Holland) operated at $100 \mathrm{kV}$ [40] TEM was also used to study the selected area electron diffraction (SAED) pattern of the Ds-AgNPs and to get best SAED pattern, the image mode was maintained by $Z$ control (sample height) while the objective lens and standard current were kept. The diffraction spots and the size of the Ds-AgNPs were determined using SIS imaging software (Munster, Germany). X-Ray Diffractometry (XRD) analysis was done to verify the crystalline nature of the Ds-AgNPs using $\mathrm{Cu}^{2+} \mathrm{Ka}$ radiation source on an Ultima IV X-ray powder diffractometer (Rigaku Ltd, Tokyo, Japan). Energy dispersive X-ray (EDAX) was also performed by Oxford Inca Penta FeTX3 EDS instrument attached to Carl Zeiss EVO MA 15 Scanning Electron Microscope (200 kV) machine with a line resolution 2.32 (in $\AA$ ). The analysis was done by coating a drop of purified Ds-AgNPs on an aluminum foil.

\subsection{In vitro antioxidant activity}

\subsubsection{Free radical scavenging activity of Ds-AgNPs by DPPH method}

Free radical scavenging activity of the Ds-AgNPs was determined by using 2, 2'- diphenyl-1-picrylhydrazyl (DPPH) radical scavenging assay according to the method described by Mittal et al [26]. The DPPH stock solution was prepared by dissolving $4 \mathrm{mg}$ of DPPH in $100 \mathrm{ml}$ of methanol and stored at $20^{\circ} \mathrm{C}$. DPPH solution ( $2 \mathrm{ml}$ ) was added to $1 \mathrm{ml}$ of methanol solution containing test samples of Drosera spatulata Labill var. bakoensis plant extract and biosynthesized Ds-AgNPs at different concentrations of $25 \mu \mathrm{g} / \mathrm{ml}, 50 \mu \mathrm{g} / \mathrm{ml}, 75 \mu \mathrm{g} / \mathrm{ml}$ and $100 \mu \mathrm{g} / \mathrm{ml}$. The radical scavenging activity (RSA) was calculated by determining the absorbance at $517 \mathrm{~nm}$, by using standard ascorbic acid, the antioxidant activity was expressed as $\mathrm{IC}_{50}$. The $\mathrm{IC}_{50}$ is the half maximum inhibitory concentration of any substance inhibiting a specific biological process or function.

RSA $(\%)=[($ control absorbance-sample absorbance $) /($ control absorbance $)] \times 100$ 


\subsubsection{Hydrogen peroxide $\left(\mathrm{H}_{2} \mathrm{O}_{2}\right)$ scavenging activity}

$\mathrm{H}_{2} \mathrm{O}_{2}$ scavenging ability of the Drosera spatulata Labill var. bakoensis plant extract and biosynthesized DsAgNPs at different concentrations of $25 \mu \mathrm{g} / \mathrm{ml}, 50 \mu \mathrm{g} / \mathrm{ml}, 75 \mu \mathrm{g} / \mathrm{ml}$ and $100 \mu \mathrm{g} / \mathrm{ml}$, was examined according to the modified method of Pick and Mizel [27]. $\mathrm{H}_{2} \mathrm{O}_{2}(40 \mathrm{mM})$ solution was prepared in phosphate buffer (pH 7.4), Ds-AgNPs and plant extract at different concentrations of $25 \mu \mathrm{g} / \mathrm{ml}, 50 \mu \mathrm{g} / \mathrm{ml}$, $75 \mu \mathrm{g} / \mathrm{ml}$ and $100 \mu \mathrm{g} / \mathrm{mL}$ in $3.4 \mathrm{ml}$ phosphate buffer were added to $\mathrm{H}_{2} \mathrm{O}_{2}$ solution $(0.6 \mathrm{ml}, 40 \mathrm{mM})$. The absorbance of the reaction mixture was recorded at $230 \mathrm{~nm}$ and the percent of scavenging activity of $\mathrm{H}_{2} \mathrm{O}_{2}$ was determined using the -equation as defined for DPPH scavenging activity.

\subsubsection{Nitric oxide (NO) scavenging activity}

The Nitric oxide scavenging activity was carried out by a tailored method of Ferreira et al [28]. Nitric oxide radicals (NO) were generated from sodium nitroprusside. Sodium nitroprusside ( $1 \mathrm{ml}$ of $10 \mathrm{mM}$ ) and 1.5 $\mathrm{ml}$ of phosphate buffer saline (0.2 M, pH 7.4) were added to different concentrations $(25,50,75$ and 100 $\mu \mathrm{g} / \mathrm{mL}$ ) of the Ds-AgNPs and plant extract of Drosera spatulata Labill var. bakoensis and incubated for $150 \mathrm{~min}$ at $25^{\circ} \mathrm{C}$. The reaction mixture $(1 \mathrm{ml})$ was treated with $1 \mathrm{ml}$ of Griess reagent ( $1 \%$ sulfanilamide, $2 \% \mathrm{H}_{3} \mathrm{PO}_{4}$ and $0.1 \%$ naphthylethylenediamine dihydrochloride). The absorbance of the reaction mixture was measured at $546 \mathrm{~nm}$ and nitric oxide scavenging activity was calculated using the equation as defined for DPPH scavenging activity.

\subsection{Antimicrobial activity}

\subsubsection{Antibacterial activity}

The antibacterial activity of Ds-AgNPs was evaluated against three different strains of Gram negative Escherichia coli as follows: E.coliStrain-I (Donor) rifampin resistant, E.coli AB1157 (Mutant) streptomycin resistant and E.coli (Recipient strain) streptomycin resistant by the disc diffusion method according to modified protocol Kotakadi et al [10]. Fresh bacterial cultures were prepared by transferring single colony of respective bacterial culture into a tubes containing $20 \mathrm{ml}$ nutrient broth separately (Himedia, $\mathrm{gm} / \mathrm{L}$ ) and cultured overnight at $37^{\circ} \mathrm{C}$ in an incubator come shaker. Three replicates of individual microorganisms were prepared by spreading $200 \mu \mathrm{l}$ of culture on the nutrient agar plate with the help of sterile glass spreader. Discs were prepared by using Whatmann No.1 filter paper. The discs were placed on agar plates and sample plant extract of Drosera spatulata Labill var. bakoensis $30 \mu \mathrm{l}$ and biosynthesized Ds-AgNPs $15 \mu \mathrm{l}$ and $30 \mu \mathrm{l}(\mu \mathrm{l}=\mathrm{mcg})$ were added on the disc with the help of micropipette. Amoxyclav (Himedia SD063, $30 \mathrm{mcg}$ ) disc was used as reference drug. The plates were incubated at $37^{\circ} \mathrm{C}$ overnight in an bacteriological incubator. The zones of inhibition (ZOI) of Ds-AgNPs along with standard drug were measured and tabulated. 


\subsubsection{Antifungal activity}

The antifungal activity of Ds-AgNPs was evaluated against two fungal species Aspergillus niger and Penicillium $s p$ at concentration of $25 \mathrm{mcg}$ by disc diffusion method along with the reference drug Nystatin, (SD025, HiMedia). according to modified protocol Gaddam et al [6]. The ZOI of DsAgNPs, ZOI of standard drug Nystatin, (SD025, HiMedia) and the ZOI of plant extract of Drosera spatulata Labill var. bakoensis and $0.002 \mathrm{M}$ silver nitrate solution were analyzed, and the results were tabulated.

\subsection{Cell culture}

\section{MTT In vitro Assay for Cytotoxicity of Ds-AgNPs}

The cytotoxic activity of biosynthesized Ds-AgNPs was measured by using MTT [3-(4, 5-dimethylthiazol2-yl)-2, 5-diphenyl tetrazolium bromide assay [29]. Human colon cancer cell lines (HT-29) were obtained from the National Centre for Cellular Sciences, Pune, India. Cells were cultured in Eagle's Minimum Essential Medium, supplemented with $10 \%$ fetal bovine serum, $2 \mathrm{mM}$ glutamine, $1 \mathrm{mM} \mathrm{NaHCO}{ }_{3}, 100$ $\mu \mathrm{g} / \mathrm{mL}$ streptomycin and 100 units $/ \mathrm{mL}$ penicillin. The cell lines were maintained at $37^{\circ} \mathrm{C}$ in presence of $5 \% \mathrm{CO}_{2}$ atmosphere in an incubator. The cytotoxic assay was carried out by our previous protocol explained in recent research articles $[35-36,40]$ with different concentration of Ds-AgNPs. Approximately $2 \times 10^{4} \mathrm{HT}-29$ colon cancer cells were seeded in each well of 96 well culture plate containing $100 \mu \mathrm{L}$ of medium. After overnight incubation, exactly $100 \mu \mathrm{L}$ of Ds-AgNPs at different concentrations $(0,12.5,25$, 50,100 and $200 \mu \mathrm{g} / \mathrm{ml}$ ) were added to the cell suspension and incubated for $24 \mathrm{~h}$. After $24 \mathrm{~h}$ of incubation, the viability of cells was assessed by adding $10 \mu \mathrm{L}$ of MTT $(5 \mathrm{mg} / \mathrm{mL})$ per well and incubated at $37^{\circ} \mathrm{C}$ for additional $3 \mathrm{~h}$. The 96 well plates were centrifuged at $1000 \mathrm{xg}$ for $10 \mathrm{~min}$ at room temperature. Formazan blue that formed in the cells was dissolved using $100 \mu \mathrm{L}$ of DMSO. The intensity of color formation was measured at $570 \mathrm{~nm}$ wavelength. The percentage of inhibition of cell viability was determined and the $\mathrm{IC}_{50}$ concentrations were calculated.

\section{Results And Discussion}

\subsection{Spectral characterization of Ds-AgNPs}

\subsubsection{UV- Visible spectral analysis}

UV-Vis spectroscopy is the key method recommended to find out the possible characteristics of biofabricated silver nanoparticles (AgNPs). In the current investigation, color less plant extract of Drosera spatulata Labill var. bakoensis color was changed to pale reddish brown and later to murky brown in color within couple of minutes after addition of $0.002 \mathrm{M}$ silver nitrate solution shown in Fig.1B.(a)(b). The 
above reaction clearly proves that the plant extract consists of several bioactive components which have a very good potential in the reduction of $0.002 \mathrm{M}$ silver nitrate into silver nanoparticles i.e Ds-AgNPs. The SPR spectrum of biosynthesized Ds-AgNPs was detected at $427 \mathrm{~nm}$ (Fig.1C. Ds-Plant Extract, Ds-AgNPs).

It is well-known that the metallic silver nanoparticles have SPR region in-between $390 \mathrm{~nm}$ to $470 \mathrm{~nm}$. At the same time the AgNPs having the SPR spectrum in the region of $410-450 \mathrm{~nm}$ can be approved to have spherical nanoparticles [30], and the biosynthesized AgNPs having SPR absorption peaks around 390-420 nm and above have found that the size of nanoparticles between 25-50 nm [31]. In the present study, the SPR absorption peaks of Ds-AgNPs was observed and recorded at $427 \mathrm{~nm}$. It is also well known that different constituents of plant bioactive compounds such as flavanoids, phenols, alkaloids and sugars, etc are responsible for capping and stabilizing of metal nanoparticle by using biological extracts [32].

\subsubsection{FTIR analysis of biosynthesized Ds-AgNPs}

FTIR analysis of Drosera spatulata Labill var. bakoensis plant extract and Ds-AgNPs were analyzed separately to investigate the functional groups responsible for bio-reduction and stabilization of DsAgNPs and the results are shown in Fig.2.a,b. The FTIR spectra of plant extract of Drosera spatulata Labill var. bakoensis, showing the following functional peaks; $3867.65 \mathrm{~cm}^{-1}, 3740.25 \mathrm{~cm}^{-1}$, $3424.94 \mathrm{~cm}^{-1}, 2924.06 \mathrm{~cm}^{-1}, 2856.05 \mathrm{~cm}^{-1}, 2312.87 \mathrm{~cm}^{-1}, 1630.06 \mathrm{~cm}^{-1}, 1383.14 \mathrm{~cm}^{-1}, 1066.51 \mathrm{~cm}^{-1}$ and $688.07 \mathrm{~cm}^{-1}$ were observed and FTIR spectra of biosynthesized Ds-AgNPs revealed the following functional groups; $3418.17 \mathrm{~cm}^{-1}, 2924.54 \mathrm{~cm}^{-1}, 1614.25 \mathrm{~cm}^{-1}, 1414.25 \mathrm{~cm}^{-1}, 1069.06 \mathrm{~cm}^{-1}$ and 667.33 $\mathrm{cm}^{-1}$. The functional groups of biomolecules were identified after bio-reduction of $\mathrm{Ag}^{+}$to silver nanoparticles i.e. Ds-AgNPs as capping and stabilizing molecules. The functional groups in plant extract of Drosera spatulata at $3424 \mathrm{~cm}^{-1}$ corresponds to $0-\mathrm{H}$ stretching of vibrations, indicating the existence of alcohols and phenols while peaks at $2924.06 \mathrm{~cm}^{-1}$ and $2856.05 \mathrm{~cm}^{-1}$ belong to $\mathrm{C}-\mathrm{H}$ region arising from the stretching and bending of aromatic compounds. The peak at $2312.87 \mathrm{~cm}^{-1}$ corresponds to $\mathrm{C}-\mathrm{H}$ stretching of methyl, methylene groups and methoxy groups, while $1630.06 \mathrm{~cm}^{-1}$ due to the stretching of $\mathrm{C}-\mathrm{N}$ and $\mathrm{C}-\mathrm{C}$, indicating the presence of protein. Also, $1383.14 \mathrm{~cm}^{-1}$ belongs to typical stretching of $\mathrm{N}=0$, which corresponds to nitro compounds, $1066.51 \mathrm{~cm}^{-1}$ corresponds to $\mathrm{C}-\mathrm{N}$ vibration stretches of amines, which belongs to protein and $667.33 \mathrm{~cm}^{-1}$ belongs to $\mathrm{C}-\mathrm{H}$ bending and $\mathrm{C}=\mathrm{C}-\mathrm{H}$ stretching vibrations of amides. Whereas the functional groups of Ds-AgNPs at $3418.17 \mathrm{~cm}^{-1}$ corresponds to $\mathrm{O}-\mathrm{H}$ stretching indicating presence of alcohols and Phenols while peaks at $2924.54 \mathrm{~cm}^{-1}, 1614.25 \mathrm{~cm}^{-1}$ due to the stretching of $\mathrm{C}-\mathrm{N}$ and $\mathrm{C}-\mathrm{C}$ indicating the presence of proteins. The peaks at $1414.25 \mathrm{~cm}^{-1}$ may be due to vibration stretches of $=\mathrm{CH}-\mathrm{H}$ belongs alkanes and $\mathrm{C}-\mathrm{O} / \mathrm{C}-\mathrm{H}$ bending of alkanes. Also $1069.06 \mathrm{~cm}^{-}$

${ }^{11}$ corresponds to $\mathrm{C}-\mathrm{N}$ vibration stretches of amines which belongs to proteins and $667.33 \mathrm{~cm}^{-1}$ belongs to $\mathrm{C}-\mathrm{H}$ bending $\mathrm{C} \equiv \mathrm{C}-\mathrm{H}$ stretching vibrations of amides. So, from the above results it can be concluded that $\mathrm{O}-\mathrm{H}$ stretching of alcohols and Phenols, $\mathrm{C}-\mathrm{N}$ and $\mathrm{C}-\mathrm{C}$ of the proteins, $=\mathrm{CH}-\mathrm{H}, \mathrm{C}-\mathrm{O} / \mathrm{C}-\mathrm{H}$ bending of alkanes, 
$\mathrm{N}=\mathrm{O}$ which corresponds to nitro compounds and $\mathrm{C}-\mathrm{H}$ bending $\mathrm{C} \equiv \mathrm{C}-\mathrm{H}$ stretching vibrations of amides present in the plant extract might be responsible for the bio-reduction of $\mathrm{Ag}^{+}$to AgNPs i.e Ds-AgNPs. Similar results were reported on FTIR analysis by biosynthesized silver nanoparticles by other plant resources [33-36].

\subsubsection{Particle size and Zeta potential of biosynthesized Ds- AgNPs}

The particle size and zeta potential of the biosynthesized Ds-AgNPs was measured using dynamic light scattering (DLS) method to determine the size distribution and electrical charge present on the surface of Ds-AgNPs. Our results revealed that the size distribution of biosynthesized Ds-AgNPs was between $15 \mathrm{~nm}$ to $40 \mathrm{~nm}$ with an average size of $21.9 \mathrm{~nm}$ (Fig.3.a) indicating that biosynthesized Ds-AgNPs are poly dispersed in nature. The zeta potential of Ds-AgNPs was detected to be $-32.6 \mathrm{mV}$ (Fig.3.b), due to its high negative potential the nanoparticles are well dispersed in biosynthesized colloidal solution. The stability of the Ds-AgNPs was due to their similar charges on the surface which will oppose the agglomeration. When the zeta potential is lower the attraction between nanoparticles exceeds repulsion and promotes aggregation of the nanoparticles. The zeta potential of silver nanoparticles using other plants also exhibit similar type of results [37-38]. Therefore the Ds-AgNPs are highly stable and well dispersed in the biosynthesized colloidal solution.

\subsubsection{Transmission electron microscopic analysis of biosynthesized Ds-AgNPs}

TEM analysis provides the images of nanoparticles and these images are helpful to find out the size, shape, surface morphology, texture, and distribution of nanoparticles. The results revealed that the DsAgNPs were roughly sphere-shaped with variations in size distribution, The bio-nanoparticles Ds-AgNPs are in the range from $5 \mathrm{~nm}$ to $40 \mathrm{~nm}$ at different magnifications [Fig.4.a,b,c,d]. The Ds-AgNPs TEM images revealed that the nanoparticles are poly dispersed in nature without any agglomeration. The variation in size and shape of biosynthesized nanoparticles may be due to the presence of bioactive molecules of the plant extract present on the surface of the Ds-AgNPs. The Ds-AgNPs crystal analysis at $2 \mathrm{~nm}$ resolution revealed the crystal lattice fringes with the $\mathrm{d}$ spacing value of $0.223 \mathrm{~nm}$ [Figure 4.e].

Later on, the crystal analysis done by SAED pattern [Figure.4.f] showed evidently Debye-Scherer rings of different planes of face centric cubic structures. With the above results it is concluded that the biosynthesized Ds-AgNPs are crystalline in nature, the results were similar to the earlier reports of biosynthesized AgNPs by leaf extracts of Andrographis serpyllifolia and also fruit extract of Terminalia belerica [39-40].

\subsubsection{XRD analysis of biosynthesized Ds-AgNPs}


$X$-ray diffraction analysis of Ds-AgNPs was done to find out the crystalline characteristics of nanoparticles [Figure.5.a]. The spectral analysis of the Ds-AgNPs revealed diffraction peaks at $38.7^{\circ}$, $44.9^{\circ}, 65.3^{\circ}$ and $78.4^{\circ}$ and were respectively indexed to planes of face centered cubic (FCC) crystal lattice (111) (200) (220) and (311). The XRD outcome is consistent with standard JCPDS data (JCPDS No.030931).

\subsubsection{Energy Dispersive X-ray Spectroscopy (EDX) analysis of biosynthesized Ds-AgNPs}

The EDX analysis of biosynthesized Ds-AgNPs revealed that Ds-AgNPs exhibited very strong signal of silver [Figure.5.b], oxygen and weak signals $\mathrm{Si}$ and chlorine peaks, indicating the complete reduction of silver ions to elemental silver. Likewise, the previous reports on silver nanoparticles revealed similar results in EDX analysis. The Ds-AgNPs showed high emission energy at $3 \mathrm{keV}$ for silver and insubstantial signals for other elements.

\subsubsection{Atomic Force Microscopy analysis (AFM) analysis of biosynthesized Ds-AgNPs}

The AFM analysis of biosynthesized Ds-AgNPs was done to detect the surface morphology and topology of nanoparticles. The results indicated that the Ds-AgNPs are spherical in shape and the size of the DsAgNPs were in the range of $5 \mathrm{~nm}$ to $30 \mathrm{~nm}$ and the average grain size detected as $23 \pm 5 \mathrm{~nm}$ [Fig.6.a,b]. Further, we have also carried out Z-coloration analysis with 3D image of Ds-AgNPs to find out the distribution of different size of biosynthesized Ds-AgNPs. The results clearly indicate that the Ds-AgNPs are in the range of $5 \mathrm{~nm}$ to $30 \mathrm{~nm}$ [Fig.6c], It is concluded that the size of Ds-AgNPs almost similar to that of Particle size analysis and TEM analysis.

\subsection{In vitro antioxidant activity of Ds-AgNPs by $\mathrm{DPPH}, \mathrm{H}_{2} \mathrm{O}_{2}$ and Nitric oxide (NO) methods}

In the present study antioxidant activity of Dorsera spatulata Labill var. bakoensis plant extract (Ds-PE) and Ds-AgNPs was determined by three important assays namely DPPH assay, $\mathrm{H}_{2} \mathrm{O}_{2}$ assay and NO scavenging assays. The results were shown in Table.1.(i) \& Fig.7.(a) DPPH assay [Table.1.(ii) \& Fig.7.(b)] $\mathrm{H}_{2} \mathrm{O}_{2}$ free radicals assay and Table.1.(iii) \& Fig.7.(c) Nitric oxide assay for both the Dorsera spatulata plant extract (Ds-PE) and biosynthesized Ds-AgNPs. The results revealed that DPPH assay is the best antioxidant assay with utmost inhibition of free radicals at the percentage of $62 \%$ and $76 \%$ for both (Ds-PE) and Ds-AgNPs, with an $\mathrm{IC}_{50}$ values calculated at the highest concentration of $100 \mu \mathrm{g} / \mathrm{mL}$ is as follows $42.2 \mu \mathrm{g} / \mathrm{mL}$ for DS-PE) and $29.27 \mu \mathrm{g} / \mathrm{mL}$ for (Ds-AgNPs). Similarly, the $\mathrm{H}_{2} \mathrm{O}_{2}$ antioxidant assay reveals that both the DsPE and Ds-AgNPs show good scavenging activity of $47 \%$ and $56 \%$ against 
$\mathrm{H}_{2} \mathrm{O}_{2}$ radicals with an $\mathrm{IC}_{50}$ values $45.25 \mu \mathrm{g} / \mathrm{mL}$ and $35.2 \mu \mathrm{g} / \mathrm{mL}$ respectively for Ds-PE and Ds-AgNPs. Lastly in NO free radical assay, DsPE and Ds-AgNPs exhibited very good scavenging activity of $54.4 \%$ and $62.78 \%$ against $\mathrm{NO}$ free radicals, with an $\mathrm{IC}_{50}$ values of $48.4 \mu \mathrm{g} / \mathrm{mL}$ and $36.2 \mu \mathrm{g} / \mathrm{mL}$. From the above results it is clearly understood that the antioxidant activity was dose dependent manner in all the three methods, and the data revealed that the DPPH showed superior antioxidant activity when compared with other two methods, followed by $\mathrm{NO}$ free radical assay and $\mathrm{H}_{2} \mathrm{O}_{2}$ antioxidant activity. So finally it is concluded that efficient DPPH scavenging activity of Ds-AgNPs could be due to the proteins, polyphenols and flavonoids which are present plant extract. Proteins, alcohols and Phenols might have actively participated in the green synthesis of Ds-AgNPs. Proteins might be involved in the coating and capping of the Ds-AgNPs, because the Drosera spatulata Labill var. bakoensis plant is an insectivorous plant which is rich in proteins and other bioactive compounds. The roles of plant extract and Ds-AgNPs in antioxidant activity have been shown in schematic diagram S.2. below

\subsection{Antimicrobial activity of biosynthesized Ds-AgNPs}

\subsubsection{Antibacterial activity}

The antibacterial studies of the biosynthesized Ds-AgNPs was carried out by using three different strains antibiotic resistant gram negative Escherichia coli. The strains are as follows E.coli mutant strain, E.coli donor strain and E.coli recipient strain. The Ds-AgNPs were found have very efficient antibacterial activity against the three Escherichia coli bacterial strains at the concentration of $30 \mu \mathrm{l}(30 \mathrm{mcg})$. The zone of inhibition (ZOI) of Ds-AgNPs with different concentration of $15 \mathrm{mcg}$ and $30 \mathrm{mcg}$ were reported in Table.2., by comparing along with standard antibiotic viz. Amoxyclav (Himedia SD063) and plant extract.

The ZOI of Amoxyclav (Himedia SD063) in all three strains of antibiotic resistant E.coli mutant strain, E.coli donor strain and E.coli recipient strain were $22 \mathrm{~mm}, 24 \mathrm{~mm}$ and $20 \mathrm{~mm}$, whereas the ZOI of DsAgNPs at the concentration of $30 \mathrm{mcg}$ were $26 \mathrm{~mm}, 30 \mathrm{~mm}$ and $26 \mathrm{~mm}$ [Fig.8.(a) \& (b)] . So, it is clearly understood that the Ds-AgNPs comprise higher inhibitory activity then the standard antibiotic Amoxyclav. Though there are several reports on antimicrobial activity of silver nanoparticles which are biofabricated or green synthesized by different parts of plant materials, revealed that in the majority of the cases the plant extracts show negligible amount of antimicrobial activity or no inhibition of bacteria, while the biosynthesized AgNPs revealed enhanced and exceptional antimicrobial activity. In the present study also, the Ds-PE showed minimum inhibition zones of $07 \mathrm{~mm}, 08 \mathrm{~mm}$, and $06 \mathrm{~mm}$ respectively, but the biosynthesized Ds-AgNPs revealed superior antibacterial activity when compared to Ds-PE alone.

When the bacterial cells are treated with AgNPs, which are in nano-size particles will come in contact with bacterial cell wall and cause cell damage by penetrating into the cell wall due to electrostatic forces and endocytosis, subsequently cause bacterial cell death by production of reactive oxygen species which cause inflammation, lead to DNA damage and other cell organelles, it's also depends upon the concentration of silver nanoparticles used for the assay, higher the concentration of AgNPs superior zone 
of inhibition was observed by various researchers. Similar type of results was observed AgNPs biosynthesized with turmeric extracts [41]. Other recent study by root extract of Salvadora persica mediated silver nanparticles, also reveals that ZOI will also depend upon the size of the nanoparticles and concentration of nanoparticles. Smaller the size of nanoparticles more easily the nanoparticles will percolate through the cell membrane and induce toxicity and cause cell death in both gram positive Staphylococcus epidermidis and gram negative Escherichia coli bacteria [42]. In the past Kim et al and Feng et al also studied the antibacterial efficacy of silver nanocomposite hydrogels and mechanistic effect of AgNPs against Escherichia coli and Staphylococcus aureus also reveals similar results in which protein synthesis is arrested due AgNPs [43-44] In another study silver nanoparticles synthesized using Cynodon dactylon leaves also revealed that, the AgNPs will reacts with proteins of bacterial wall and penetrate to cells and cause DNA damage and inhibit DNA replication [45]. Erick et al also investigate antibacterial activity against both Gram+ve and Gram-ve bacteria in an dose dependent manner [46].

\subsubsection{Antifungal activity of Ds-AgNPs}

The biosynthesized Ds-AgNPs have proved to be exceptionally lethal against two fungal species Aspergillus niger and Penicillium sp at the concentration of 25mcg [Fig.8.(c).]. The outcome of the inhibitory activity of biosynthesized Ds-AgNPs were tabulated in (Table.3) and shown in [Fig.8.(d)] along with the reference drug Nystatin, (SD025, HiMedia). The biosynthesized Ds-AgNPs showed excellent ZOI against Aspergillus niger is $20 \mathrm{~mm}$ and $16 \mathrm{~mm}$ Penicillium sp, whereas ZOI of standard drug Nystatin, (SD025, HiMedia) against Aspergillus niger and Penicillium $s p$ were $14 \mathrm{~mm}$ and $13 \mathrm{~mm}$ in diameter. The ZOI of plant extract of Drosecera spatulata Labill var. bakoensis were $4 \mathrm{~mm}$ and $5 \mathrm{~mm}$ and $0.002 \mathrm{M}$ silver nitrate solution did not show any inhibition (Table:3.), from the above results, it is concluded that the biosynthesized Ds-AgNPs have excellent antifungal activity than the standard antifungal drug Nystatin. Therefore, the biosynthesized Ds-AgNPs can be useful as effective and excellent antifungal agent and can be widely used in pharmaceutical industries for the development of antifungal ointments and other formulations [47]. Similar type of results were reported recently by seed extract mediated AgNPs by Plantago major, in which the silver nanoparticles revealed good antifungal activity against Penicillium sp and also good antibacterial activity against E.coli also [48]. The mode of action of Ds-AgNPs was illustrated in a schematic diagram S.3. as follows; AgNPs binds with ergosterol which is a major constituent of fungal cell membrane, resulting in creation of small pores in the membrane, which causes and promotes the loss of sodium, potassium and hydrogen ions and other cellular constituents like sugars and amino acids. These subsequently blocks the several membranes bound enzymes which can further cause the death of fungal cells.

\subsection{Anticancer activity of biosynthesized Ds-AgNPs}


The ability of NPs to make a way into cells primarily depends on the physiochemical properties including shape, size and surface net charge. In the current study, the size of biosynthesized Ds-AgNPs is inbetween $12 \mathrm{~nm}-40 \mathrm{~nm}$ in size with average size of $21.9 \mathrm{~nm}$. It is well known fact that the nanoparticles having the size below $100 \mathrm{~nm}$ are said to be of biomedical importance. Similarly the nanoparticles having size $<50 \mathrm{~nm}$ are said be very efficient in anticancer activity because of their minute size they can easily taken up and penetrate deeply into the cancer cells by endocytosis subsequently and cause cell death or apoptosis and eradicate tumorogenic cells. Whereas the nanoparticle having size $>50 \mathrm{~nm}$ cannot penetrate easily in the cancer cell and cannot completely damage the cancer cells or tumorogenic cells. So it is concluded that nanoparticles of minute size have three important properties by which they can easily diffuse, deep infiltration and improved accumulation can results in complete eradication of cancer cells or tumorogenic cells [49].

In the present study, anticancer activity of the Ds-AgNPs was evaluated against HT29 human colon cancer cells by MTT assay. The results revealed that the Ds-AgNPs induced cytotoxicity in HT29 cancer cells by concentration dependent approach [Fig.9.(a)]. Higher the concentration of Ds-AgNPs decreases the cell viability of cancer cells. Ds-AgNPs showed maximum inhibition of $92 \%$ against HT29 colon cancer cells. IC $\mathrm{IC}_{50}$ values of the Ds-AgNPs were found to be $52.81 \mu \mathrm{g} / \mathrm{mL}$ against HT29 colon cancer cells. The [Fig.9.(b)] reveals the cytotoxic effects of Ds-AgNPs at concentration of $50 \mu \mathrm{g} / \mathrm{mL}$ which almost equivalent $\mathrm{IC}_{50}$ value at different time interval up to 72 hour to observe the morphological changes in the cancer cell due cytotoxic effect of the biosynthesized Ds-AgNPs. It is clearly evident that the HT 29 cancer cells completely dead after 72 hour no viable cells were observed, which proves the efficacy of biosynthesized Ds-AgNPs as an anticancer agent this may due to the minute size of DsAgNPs. Recently, Alqahtani et al also reported efficacy of biosynthesized AgNPs by lichens on HCT-116 (Human colorectal cancer cell) and MDA-MB-21 (Breast cancer cell) and FaDU (Pharynx cancer cell) by in vitro cytotoxic MTT assay also revealed similar results to our present study which is size and dose dependent [50]. Kabir et al also conducted cytotoxic studies in different cancer cell lines which were similar to the above results [51], an another study by photosynthesized AgNPs using Ficus religiosa also proved have substantial cytotoxicity against COLO205 cells [52], other study using silver nanoparticles by M. koenigii have also proven to an effective applicable drug for colon cancer [53]. Finally it could be concluded that the results of cytotoxic activity of biosynthesized Ds-AgNPs are in line with previous reports and any difference in cytotoxic assay results could vary due size, shape and concentration and different cancer cell lines.

\section{Summary And Conclusion}

In this report it was demonstrated the biofabrication of nanosized Ds-AgNPs using insectivorous plant Drosera spatulata Labill var. bakoensis extract, being the first of its kind. The biosynthesized Ds-AgNPs are spherical, well-dispersed with average range size of 10 to $20 \mathrm{~nm}$ and exhibited outstanding antimicrobial activities against clinical bacteria and fungi isolates. Furthermore, Ds-AgNPs also demonstrated superior free radical scavenging activities and strong cytotoxic potential against HT-29 
colon cancer cell lines, indicating the possibility of employing and developing Ds-AgNPs as multifaceted therapeutic agents for various clinical conditions.

\section{Declarations}

\section{Acknowledgement}

The author SAG is grateful to UGC, New Delhi for providing UGC Women Post Doctoral Fellowship and the author VSK is grateful to DST-PURSE Programme, sponsored by DST New Delhi, for providing fellowship. The corresponding author Assoc Prof Dr Pasupuleti Visweswara Rao thank Universiti Malaysia Sabah for the financial support and the grant SGA-0014-2019.

\section{Authors' contributions}

SAG and VSK contributed equally to the work. Conceptualization - VSK and PVR; Execution - SAG, VSK, GK; Data Analysis - VSK, JP, VNC, SGDVR, PVR, Draft preparation - SAG, VSK, GK; Draft editing and revision - VSK, JP, VNC, SGDVR, PVR

\section{Competing interest}

The authors declare no competing interest.

\section{References}

1. Ong, C. et al. Silver Nanoparticles in Cancer: Therapeutic Efficacy and Toxicity. Curr. Med. Chem. 20(2013) 772. PMID: 23298139

2. Mukherjee, S. et al. CR. Potential Theranostics Application of Bio-Synthesized Silver Nanoparticles (4in-1 System). Theranostics 2014; 4(3):316-335. doi:10.7150/thno.7819. Available from http://www.thno.org/v04p0316.html

3. Guo, D., Zhang, J., Huang, Z., Jiang, S. \& Gu, N. Colloidal Silver Nanoparticles Improve Anti-Leukemic Drug Efficacy via Amplification of Oxidative Stress. Colloids Surf. B Biointerfaces, 126, 198-203 https://doi.org/10.1016/j.colsurfb.2014.12.023 (2015).

4. Makarov, V. V. et al. N.O. Kalinina, Green" Nanotechnologies: Synthesis of Metal Nanoparticles Using Plants Acta Naturae 6(2014) 35. PMID: 24772325

5. Kotakadi, V. S. et al. Simple and rapid biosynthesis of stable silver nanoparticles using driedleaves of Catharanthus roseus. Linn G Donn and its anti microbial activity. Colloids Surf. B: Biointerfaces, 105, 194-198 (2013).

6. Gaddam, S. A., Kotakadi, V. S., Subba Rao, Y., Varada Reddy, A. \& Sai Gopal, D. V. R. Efficient and robust biofabrication of silver nanoparticles by cassia alata leaf extract and their antimicrobial 
activity. J Nanostruct Chem, 4, 82 (2014). 10.1007/s40097-014-0082 - 5

7. Vaidyanathan, R., Kalishwaralal, K., Gopalram, S. \& Gurunathan, S. Nanosilver-the Burgeoning Therapeutic Molecule and Its Green Synthesis. Biotechnol. Adv, 27, 924 https://doi.org/10.1016/j.biotechadv.2009.08.001 (2009).

8. Kotakadi, V. S. et al. Biofabrication of silver nanoparticles by Andrographis paniculata. Eur J Med Chem, 73, 135-140 (2014).

9. Kotakadi, V. S., Gaddam, S. A., Venkata, S. K. \& Sai Gopal, D. V. R. Ficus fruit-mediated biosynthesis of silver nanoparticles and their antibacterial activity against antibiotic resistant E. coli strains. Curr Nanosci, 1, 527-538 (2015a).

10. Kotakadi, V. S., Gaddam, S. A., Sucharitha Venkata, K. \& Sai Gopal, D. V. R. New generation of bactericidal silver nanoparticles against different antibiotic resistant Escherichia coli strains. Appl Nanosci, https://doi.org/10.1007/s13204-014-0381-7 (2015b).

11. Kotakadi, V. S., Gaddam, S. A., Sucharitha Venkata, K., Sarma, P. V. G. K. \& Sai Gopal, D. V. R. Biofabrication and spectral characterization of silver nanoparticles and their cytotoxic studies on human CD34 + ve stem cells. 3 Biotech, 6, 216 https://doi.org/10.1007/s13205-016-0532-5 (2016).

12. Pasupuleti Visweswara Rao, T. N. V. K. V., Prasad, R. A., Shiekh, S. K. \& Balam Ganapathi Narasimhulu, Cirandur Suresh Reddy, Ismail Ab Rahman, Siew Hua Gan. "Biogenic silver nanoparticles using Rhinacanthus nasutus leaf extract: synthesis, spectral analysis, and antimicrobial studies. International journal of nanomedicine, 8, 3355 (2013).

13. Hebbalalu, D., Lalley, J., Nadagouda, M. N. \& Varma, R. S. Greener Techniques for the Synthesis of Silver Nanoparticles Using Plant Extracts, Enzymes, Bacteria, biodegradable Polymers, and Microwaves. ACS Sustain. Chem. Eng, 1, 703 https://doi.org/10.1021/sc4000362 (2013).

14. Rao, P., Visweswara, D., Nallappan, K., Madhavi, S. \& Rahman Lim Jun Wei, and Siew Hua Gan. "Phytochemicals and biogenic metallic nanoparticles as anticancer agents." Oxidative medicine and cellular longevity 2016 (2016).

15. Mohan, A., Narayanan, S., Sethuraman, S. \& Krishnan, U. M. Combinations of Plant Polyphenols \& Anti-Cancer Molecules: A Novel Treatment Strategy for Cancer Chemotherapy. Anticancer Agents Med. Chem, 13, 281 https://doi.org/10.2174/1871520611313020015 (2013).

16. Schilcher, H. \& Elzer, M. (1993). "Drosera (Sundew): A proven antitussive". Zeitschrift für Phytotherapie. 14 (50): 4.

17. Oliver-Bever, B. Plants in Tropical West Africa129(Cambridge University Press, Cambridge, 1986).

18. Lewis, W. H. 1977 Medical Botany - Plants Affecting Man's Health; John Wiley \& Sons, St. Louis, Missouri. pg. 254. Plant decoction of "Drosera sp.." used in Mexico to treat toothache.

19. D'Amato, P. (1998). The Savage Garden: Cultivating Carnivorous Plants. Berkeley, California: Ten Speed Press. ISBN 0-89815-915-6.

20. Rice, B. Growing Carnivorous Plants (Timber Press, Portland, Oregon, 2006). 
21. Zhang, M. et al. (2010). "Nanofibers and nanoparticles from the insect capturing adhesive of the Sundew (Drosera) for cell attachment". Journal of Nanobiotechnology. 8 (20): 20. doi:10.1186/14773155-8-20

22. Ayuga, C. et al. "Contribución al estudio de flavonoides en D. rotundifolia L". An R Acad Farm, 51, 321-326 (1985).).

23. Wagner, H. et al. (1986). "Immunological investigations of naphthoquinone - containing plant extracts, isolated quinones and other cytostatic compounds in cellular immunosystems".Phytochem Soc Eur Symp: 43.

24. Vinkenborg, J., Sampara-Rumantir, N. \& Uffelie, O. F. (1969). "The presence of hydroplumbagin glucoside in Drosera rotundifolia L". Pharmaceutisch weekblad. 104 (3):45-9. PMID 5774641.

25. Sampara-Rumantir, N. "Rossoliside". Pharm Weekbl, 106 (35), 653-664 PMID 5566922. (1971).)

26. Mittal, A. K., Kaler, A. \& Banerjee, U. C. Nano Bio Med Eng, 4, 118 (2006).

27. Pick, E. \& Mizel, D. J Immunol Methods, 46, 211 (1981).

28. Sousa, A., Ferreira, I. C. F. R., Barros, L., Bento, A. \& Pereira, J. A. Food Sci Technol-LWT, 41, 739 (2008).

29. Mosmann, T. J Immunol Methods, 65, 55 (1983).

30. Rafiuddin, Z. Z. Silver nanoparticles to self-assembled films: green synthesis and characterization. Colloids Surf. B, 90, 48 (2012).

31. Panacek.A, L. et al. Silver colloid nanoparticles: synthesis, characterization, and their antibacterial activity. J. Phys. Chem. B, 110, 16248-16253 (2006). )

32. Shahverdi, R., Minaeian, S., Shahverdi, H. R., Jamalifar, H. \& Nohi A.A. Biosynthesis and application of silver. and gold nanoparticles. Process Biochem, 42, 919-923 (2007).

33. Litvin, V. A., Galagan, R. L. \& Minaev, B. F. Kinetic and mechanism formation of silver nanoparticles coated by synthetic humic substances. Colloids \& Surfaces A: Physicochem. Eng. Aspects, 414, 234 (2012).

34. Litvin, V. A. \& Minaev, B. F. Spectroscopy study of silver nanoparticles fabrication using synthetic humic substances and their antimicrobial activity. Spectrochimica Acta Part A Molecular and Biomolecular Spectroscopy, 108, 115 (2013).

35. Netala, V. R. et al. Biogenesis of silver nanoparticles using leaf extract of Indigofera hirsuta L. and their potential biomedical applications (3-in-1 system). Artificial Cells,Nanomedicine and Biotechnology, 46 (sup1), 1138-1148 https://doi.org/10.1080/21691401.2018.1446967 (2018).

36. Netala Vasudeva Reddy,Bethu Murali Satyanarayana,Sana Sivasankar,Duggina Pragathi Kotakadi Venkata Subbaiah and Tartte Vijaya(2020)Eco-friendly synthesis of silver nanoparticles using leaf extract of Flemingia wightiana: spectral characterization, antioxidant and anticancer activity studies. SN Applied Sciences (2020) 2:884 https://doi.org/10.1007/s42452-020-2702-7

37. Sashikiran Palithya, S. A., Gaddam, V. S. \& Varadarajulu Naidu Challagundla. Kotakadi, Josthna Penchalaneni \& (2021) Biosynthesis of silver nanoparticles using leaf extract of 
Decaschistiacrotonifolia and its antibacterial, antioxidant, and catalytic applications, Green Chemistry Letters and Reviews, 14:1, 136-151, DOI: 10.1080/17518253.2021.1876172

38. Shruti Tyagi,Pankaj Kumar Tyagi,Deepak Gola, Chauhan,Randhir, N. \& Bharti, K. (2020) Extracellular synthesis of silver nanoparticles using entomopathogenic fungus: characterization and antibacterial potential. SN Applied Sciences (2019) 1:1545 | https://doi.org/10.1007/s42452-019-1593-y

39. Palithya, S., Subbaiah Kotakadi, V., Pechalaneni, J. \& Naidu, C. V. Biofabrication of Silver nanoparticles by leaf extract of Andrographis serpyllifolia and their antimicrobial and antioxidant activity. Int. J. Nano Dimens, 9 (4), 398-407 (2018).

40. Venkata, S. K. \& Gaddam, S. A. Venkata Subbaiah Kotakadi, and Divi Venkata Ramana Sai Gopal. Multifunctional Silver Nanoparticles by Fruit Extract of Terminalia belarica and their Therapeutic Applications: A 3-in-1 System. Nano Biomed. Eng, 10 (3), 279-294 (2018). 10.5101/nbe. v10i3.p279294

41. Fouad, K. A., WeiWang, P. Z. \& AzlinMustapha, M. L. Green synthesis of silver nanoparticles using turmeric extracts and investigation of their antibacterial activities. Colloids and Surfaces $B$ : Biointerfaces, Volume, 171, 1 (November 2018).

42. Arshad, H. et al. Salvadora persica mediated synthesis of silver nanoparticles and their antimicrobial efficacy. Sci Rep, 11, 5996 https://doi.org/10.1038/s41598-021-85584-w (2021).

43. Kim, Y. et al. Synthesis, Characterization, and Antibacterial Applications of Novel Copolymeric Silver Nanocomposite Hydrogels. Bull Korean Chem Soc, 32, 553-558 (2011).

44. Feng, Q. L. et al. A mechanistic study of the antibacterial effect of silver ions on Escherichia coli and Staphylococcus aureus. J. Biomed. Mater. Res, 52, 662-668 (2000).

45. Sahu, N. et al. Synthesis and characterization of silver nanoparticles using Cynodon dactylon leaves and assessment of their antibacterial activity. Bioprocess Biosyst. Eng, 36, 999-1004 (2013).

46. Erick Pazos-Ortiz, Jose Hafid Roque-Ruiz, Efrén Amador Hinojos-Márquez, et al., “Dose-Dependent Antimicrobial Activity of Silver Nanoparticles on Polycaprolactone Fibers against Gram-Positive and Gram-Negative Bacteria," Journal of Nanomaterials, vol. 2017, Article ID 4752314, 9 pages, 2017. https://doi.org/10.1155/2017/4752314.

47. Tang, S. Jie Zheng 2018. Antibacterial Activity of Silver Nanoparticles: Structural Effects. Advanced Health care materials:Volume7, Issue13 Special Issue: Combatting Infections with Nanomedicine July 11, 2018. https://doi.org/10.1002/adhm.201701503

48. Nikaeen, G. et al. Central Composite Design for Optimizing the Biosynthesis of Silver Nanoparticles using Plantago major Extract and Investigating Antibacterial, Antifungal and Antioxidant Activity. Sci Rep, 10, 9642 https://doi.org/10.1038/s41598-020-66357-3 (2020).

49. Maharani, V., Sundaramanickam, A. \& Balasubramanian Thangavel.2016 In vitro anticancer activity of silver nanoparticle synthesized by Escherichia coli VM1 isolated from marine sediments of Ennore southeast coast of India.Enzyme and Microbial Technology, Vol.95: pages146-154

50. Alqahtani, M. A., Othman, A., Mohammed, A. E. \& M.R. \& Bio fabrication of silver nanoparticles with antibacterial and cytotoxic abilities using lichens. Sci Rep, 10, 16781 
https://doi.org/10.1038/s41598-020-73683-z (2020).

51. M. F. Kabir · A. K. M. Atique Ullah, J J. Ferdousy - M. M. Rahman.( 2020)Anticancer efficacy of biogenic silver nanoparticles in vitro. SN Applied Sciences (2020) 2:1111। https://doi.org/10.1007/s42452-020-2929-3

52. Nakkala, J. R., Rani, M. \& Sadras, S. R. Green synthesized nano silver: Synthesis, physicochemical profiling, antibacterial, anticancer activities, and biological in vivo toxicity. J Col Interface Sci, 499, 33-45 (2017).

53. Roshni, K., Younis, M., llakkiyapavai, D., Basavaraju, P. \& Puthamohan, V. M. Anticancer Activity of Biosynthesized Silver Nanoparticles using Murraya koenigii Leaf Extract against HT-29 Colon Cancer Cell Line. J Cancer Sci Ther, 10, 072-075 https://doi.org/10.4172/1948-5956.1000521 (2018).

\section{Tables}

\section{Table: 1}

\section{In vitro antioxidant activity of Ds-PE and Ds-AgNPs by DPPH method, $\mathrm{H}_{2} \mathrm{O}_{2}$ method and Nitric oxide (NO) method}

(i). In vitro antioxidant activity by DPPH method

\begin{tabular}{|lccccc|}
\hline DPPH method & \multicolumn{5}{l|}{ Radical scavenging activity \pm SD (\%) } \\
Sample name & $25 \mu \mathrm{g} / \mathrm{ml}$ & $50 \mu \mathrm{g} / \mathrm{ml}$ & $75 \mu \mathrm{g} / \mathrm{ml}$ & $100 \mu \mathrm{g} / \mathrm{ml}$ & Ic50 \\
\hline Ascorbic acid & $45.07 \pm 0.26$ & $54.73 \pm 0.07$ & $63.54 \pm 0.56$ & $67.43 \pm 0.67$ & $33.93 \pm 0.12$ \\
\hline $\begin{array}{l}\text { Dorsera spatulata plant } \\
\text { extract }\end{array}$ & $25.45 \pm 1.52$ & $42.86 \pm 1.96$ & $54.48 \pm 1.36$ & $62.10 \pm 1.34$ & $42.29 \pm 1.31$ \\
\hline Ds-AgNPs & $37.81 \pm 1.45$ & $54.91 \pm 0.36$ & $67.64 \pm 1.47$ & $76.20 \pm 0.39$ & $29.27 \pm 0.63$ \\
\hline
\end{tabular}

(ii). In vitro antioxidant activity by $\mathrm{H}_{2} \mathrm{O}_{2}$ method

\begin{tabular}{|llllll|}
\hline $\mathrm{H}_{2} \mathrm{O}_{2}$ method & \multicolumn{5}{l|}{ Radical scavenging activity \pm SD (\%) } \\
\hline Sample name & $25 \mu \mathrm{g} / \mathrm{ml}$ & $50 \mu \mathrm{g} / \mathrm{ml}$ & $75 \mu \mathrm{g} / \mathrm{ml}$ & $100 \mu \mathrm{g} / \mathrm{ml}$ & Ic50 \\
\hline $\begin{array}{l}\text { Dorsera spatulata plant } \\
\text { extract }\end{array}$ & $15.14 \pm 0.34$ & $23.4 \pm 1.24$ & $40.56 \pm 1.32$ & $47.02 \pm 1.76$ & $45 \pm 1.25$ \\
\hline Ds-AgNPs & $28.64 \pm 0.25$ & $34.64 \pm 0.6$ & $45.34 \pm 0.56$ & $56.43 \pm 1.57$ & $35.2 \pm 0.48$ \\
\hline
\end{tabular}


(iii). In vitro antioxidant activity by Nitric oxide (NO) method

\begin{tabular}{|llllll|}
\hline Nitric oxide (NO) method & \multicolumn{5}{l|}{ Radical scavenging activity \pm SD (\%) } \\
\hline Sample name & $25 \mu \mathrm{g} / \mathrm{ml}$ & $50 \mu \mathrm{g} / \mathrm{ml}$ & $75 \mu \mathrm{g} / \mathrm{ml}$ & $100 \mu \mathrm{g} / \mathrm{ml}$ & Ic50 \\
\hline $\begin{array}{l}\text { Dorsera spatulata plant } \\
\text { extract }\end{array}$ & $14.26 \pm 1.4$ & $25.6 \pm 0.14$ & $44.28 \pm 0.2$ & $54.44 \pm 0.67$ & $48.4 \pm 0.16$ \\
\hline Ds-AgNPs & $26.58 \pm 1.12$ & $36.62 \pm 1.48$ & $52.18 \pm 1.2$ & $62.78 \pm 0.22$ & $36 \pm 01.26$ \\
\hline
\end{tabular}

Table: 2

Antibacterial activity of Ds-AgNPs on antibiotic resistant E.coli

\begin{tabular}{|lllll|}
\hline Samples & $\begin{array}{l}\text { 1.Plant } \\
\text { Extract }\end{array}$ & $\begin{array}{l}\text { 2.Ds-AgNPs } \\
15 \mathrm{mcg}\end{array}$ & $\begin{array}{l}3 . \text { Antibiotic Amoxyclav } \\
30 \mathrm{mcg}\end{array}$ & $\begin{array}{l}\text { 4. Ds-AgNPs } \\
30 \mathrm{mcg}\end{array}$ \\
& Zone of Inhibition & & \\
\hline E.coli Mutant strain & $7 \mathrm{~mm}$ & $18 \mathrm{~mm}$ & $22 \mathrm{~nm}$ & $26 \mathrm{~mm}$ \\
\hline E.coli Donor strain & $8 \mathrm{~mm}$ & $21 \mathrm{~mm}$ & $24 \mathrm{~mm}$ & $30 \mathrm{~mm}$ \\
\hline E.coli recipient strain & $6 \mathrm{~mm}$ & $14 \mathrm{~mm}$ & $20 \mathrm{~mm}$ & $26 \mathrm{~mm}$ \\
\hline
\end{tabular}

Table: 3

Antifungal activity of Ds-AgNPs on Aspergillus niger and Penicillium sp

\begin{tabular}{|llrll|}
\hline & $\begin{array}{l}\text { Plant Extract } \\
(20 \mathrm{mcg})\end{array}$ & $\begin{array}{l}\text { Silver Nitrate } \\
(20 \mathrm{mcg})\end{array}$ & $\begin{array}{l}\text { Antibiotic } \\
\text { (Nystatin 20mcg) }\end{array}$ & $\begin{array}{l}\text { Ds-AgNPs } \\
(20 \mathrm{mcg})\end{array}$ \\
\hline Aspergillus niger & $4 \mathrm{~mm}$ & $\mathrm{Nil}$ & $14 \mathrm{~mm}$ & $20 \mathrm{~mm}$ \\
\hline Penicillium $s p$ & $5 \mathrm{~mm}$ & $\mathrm{Nil}$ & $13 \mathrm{~mm}$ & $16 \mathrm{~mm}$ \\
\hline
\end{tabular}

\section{Figures}



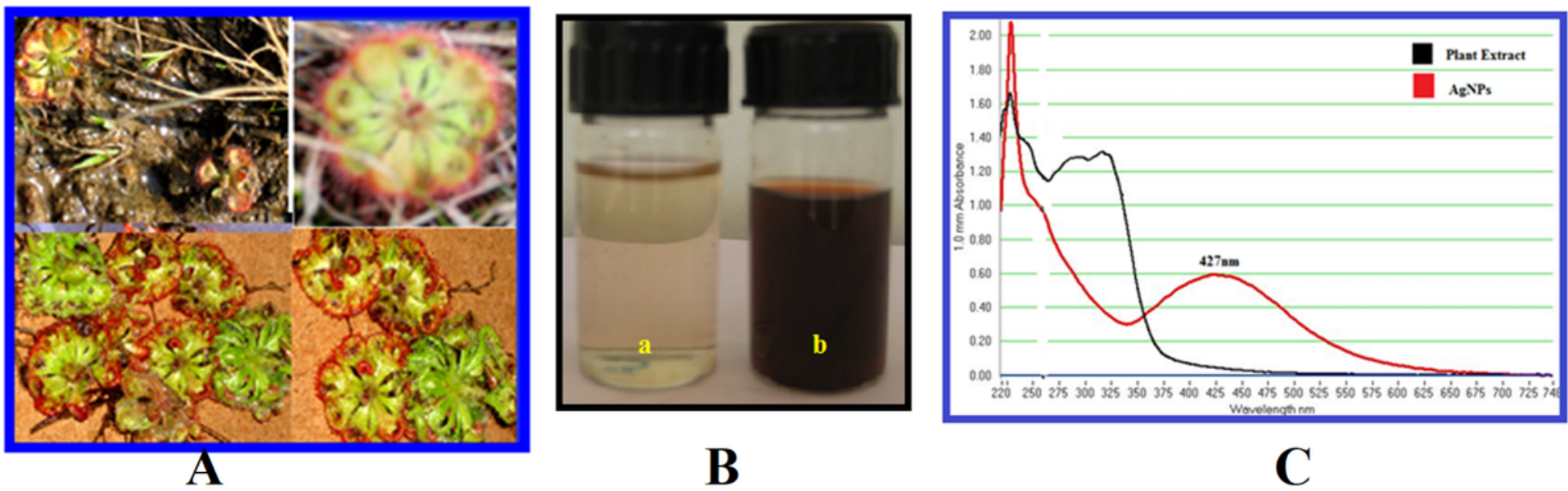

B

C

\section{Figure 1}

A. Drosera spatulata plant B. (a) Plant extract of Drosera spatulata (b). Biosynthesized Ds-AgNPs by Plant extract of Drosera spatulata C. UV-VIS absorption spectra of Drosera spatulata plant extract d. UVVIS absorption spectra of Ds-AgNps synthesized from Drosera spatulata plant extract with $0.002 \mathrm{M}$ silver nitrate.

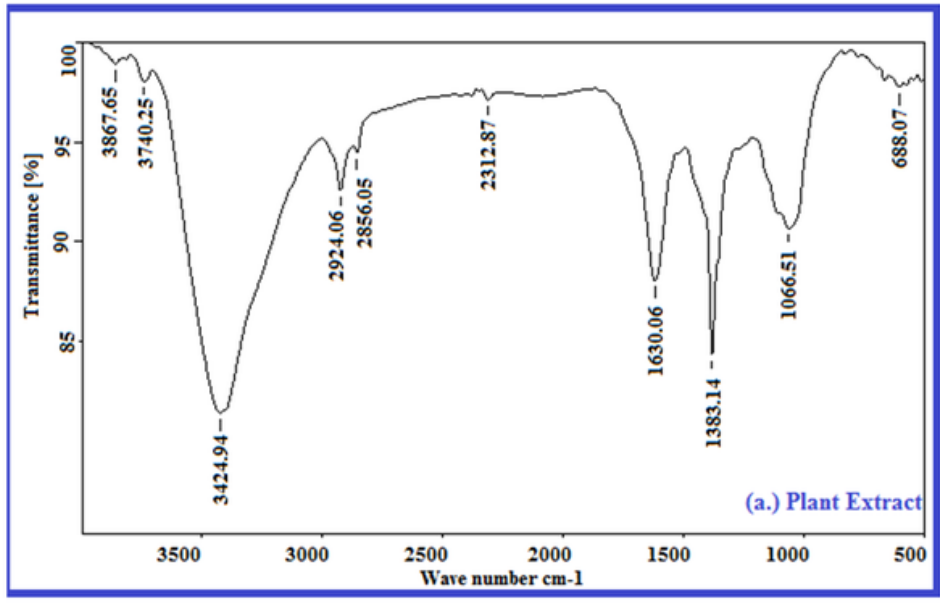

A

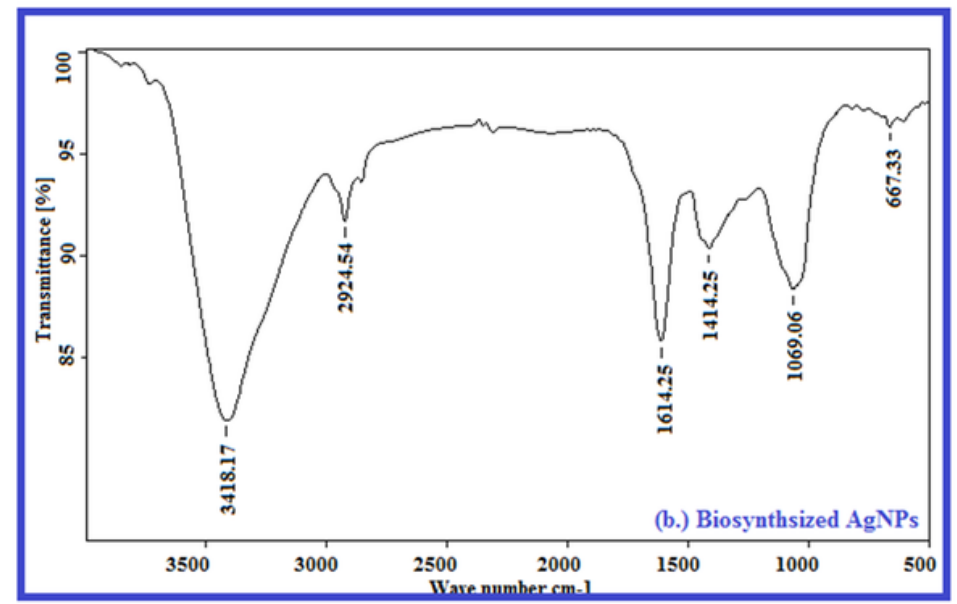

B

Figure 2

(a) FTIR spectrum of the Drosera spatulata plant extract (b) FTIR spectrum of the biosynthesized DsAgNPs of Drosera spatulata plant extract 


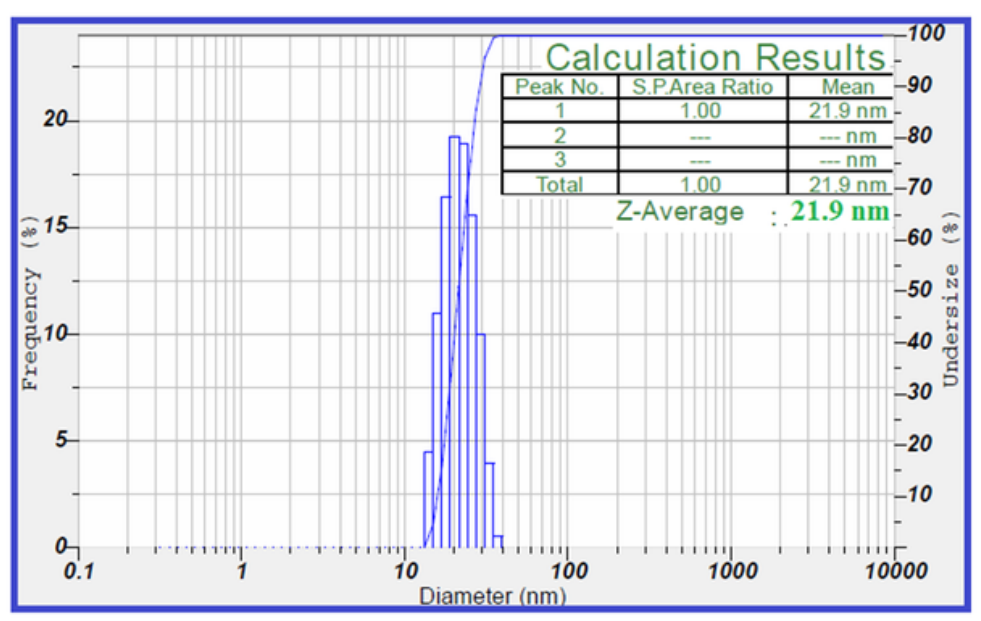

A

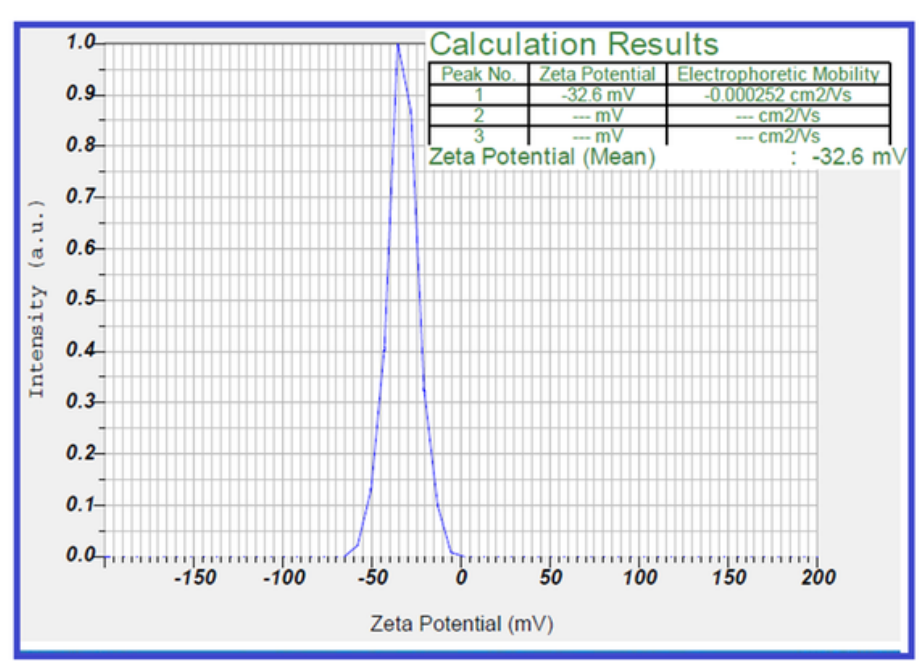

B

\section{Figure 3}

a. Particle size distribution curve for Ds-AgNPs b. Zeta potential of synthesized Ds-AgNPs

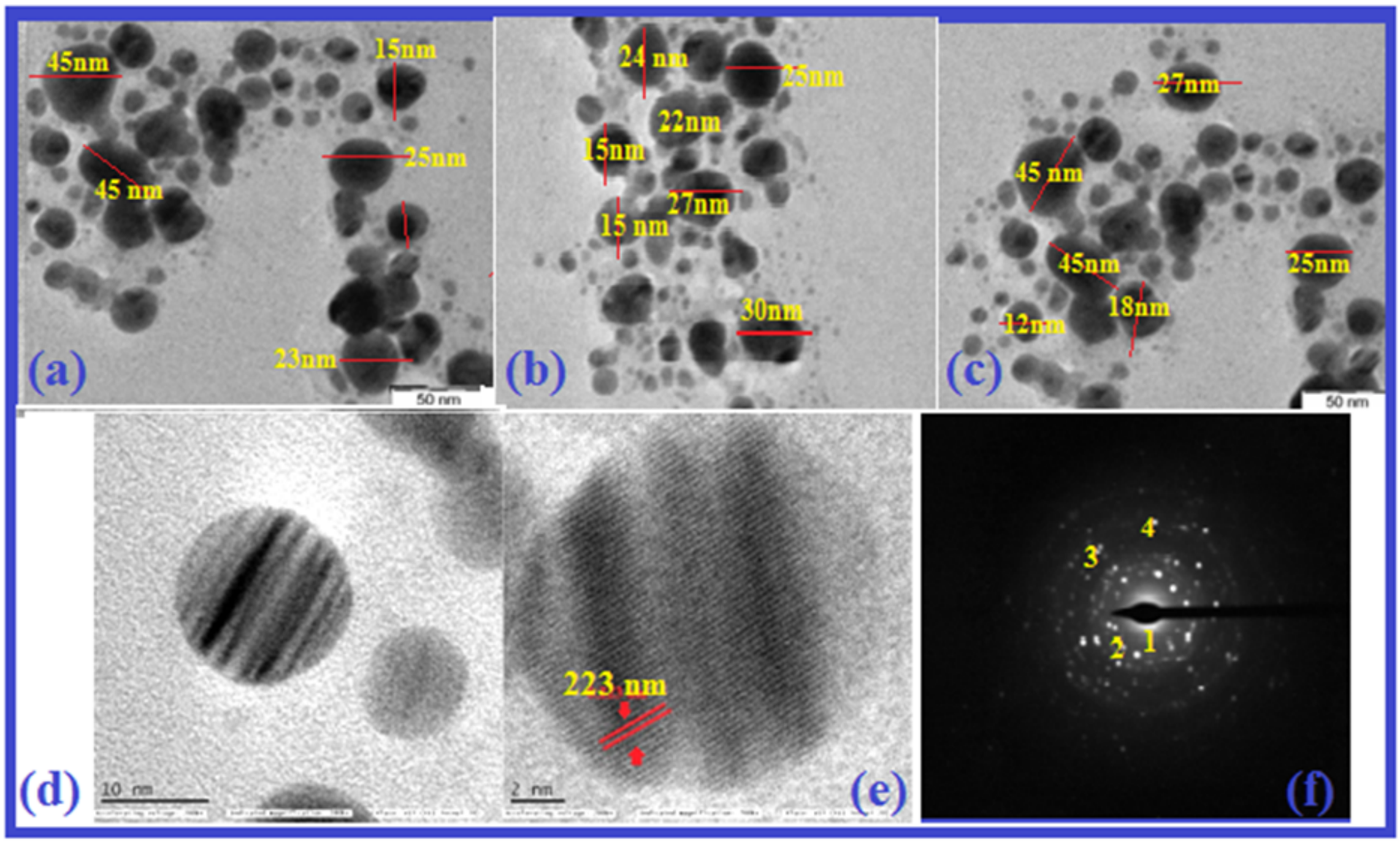

Figure 4

TEM images of Ds-AgNPs at magnification of (a) $50 \mathrm{Kx}$ (b) $50 \mathrm{Kx}$ (c) $50 \mathrm{Kx}$ (d) $280 \mathrm{Kx}$ (e) $700 \mathrm{Kx}$ (f)SAED pattern showed four diffraction rings 


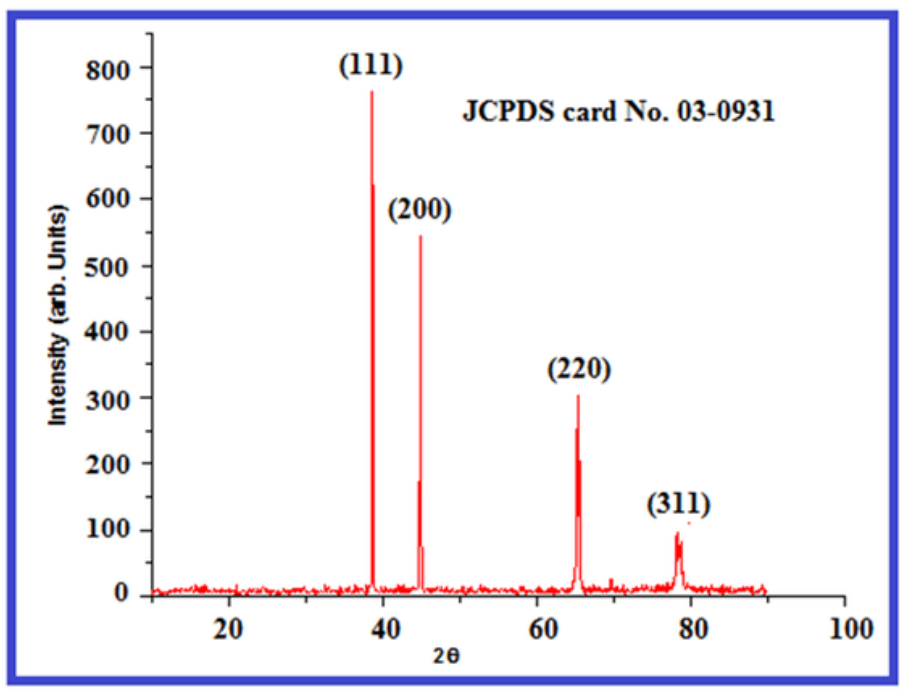

A

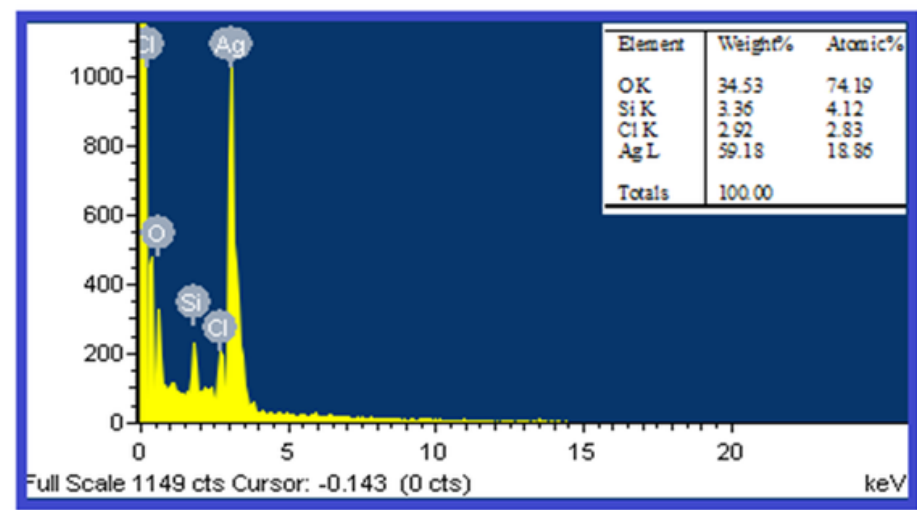

B

\section{Figure 5}

a. XRD spectral data of biosynthesized Ds-AgNPs b. EDX analysis of fabricated Ds-AgNPs by plant extract of Drosera spatulata

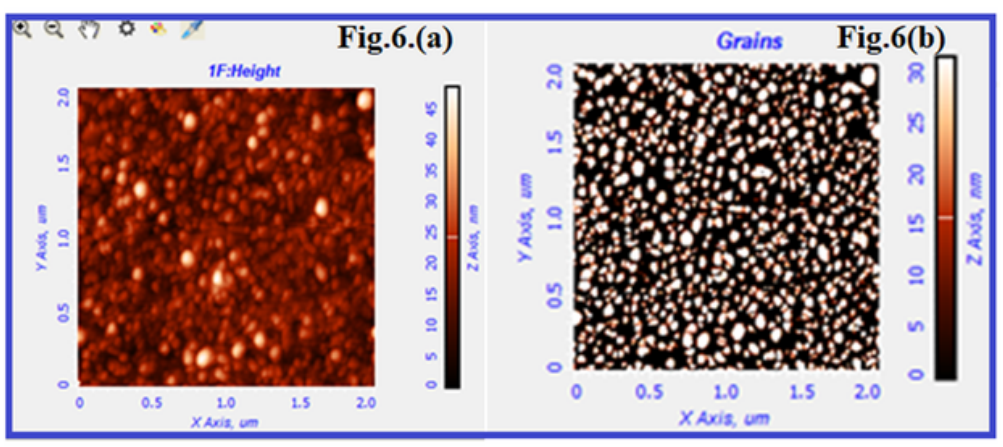

A

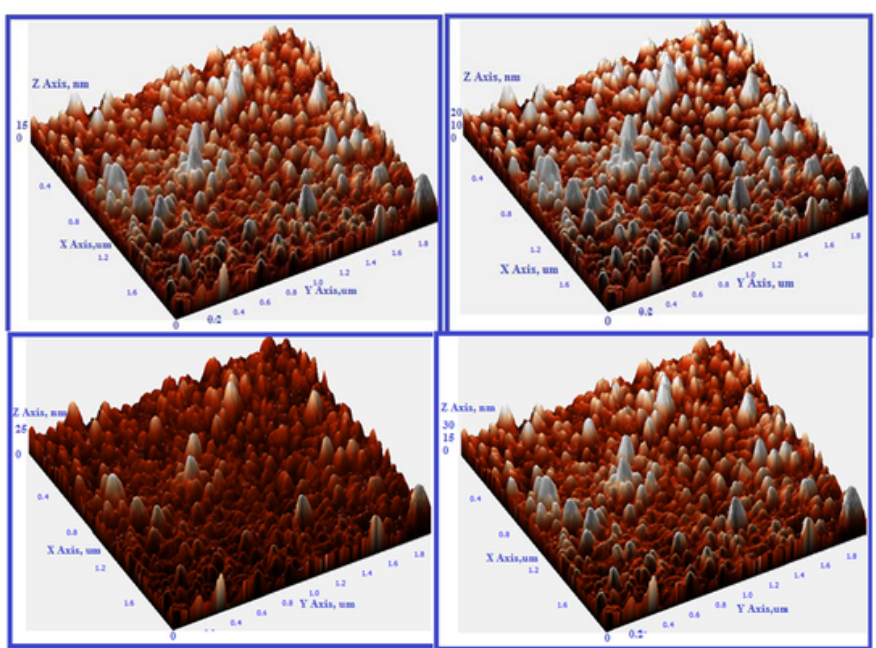

B

Figure 6

(a) 2D image of biosynthesized Ds-AgNPs (b) Grains detected (c) 3D image of biosynthesized Ds-AgNPs Grains analysis of Ds-AgNPs by Z coloration method 


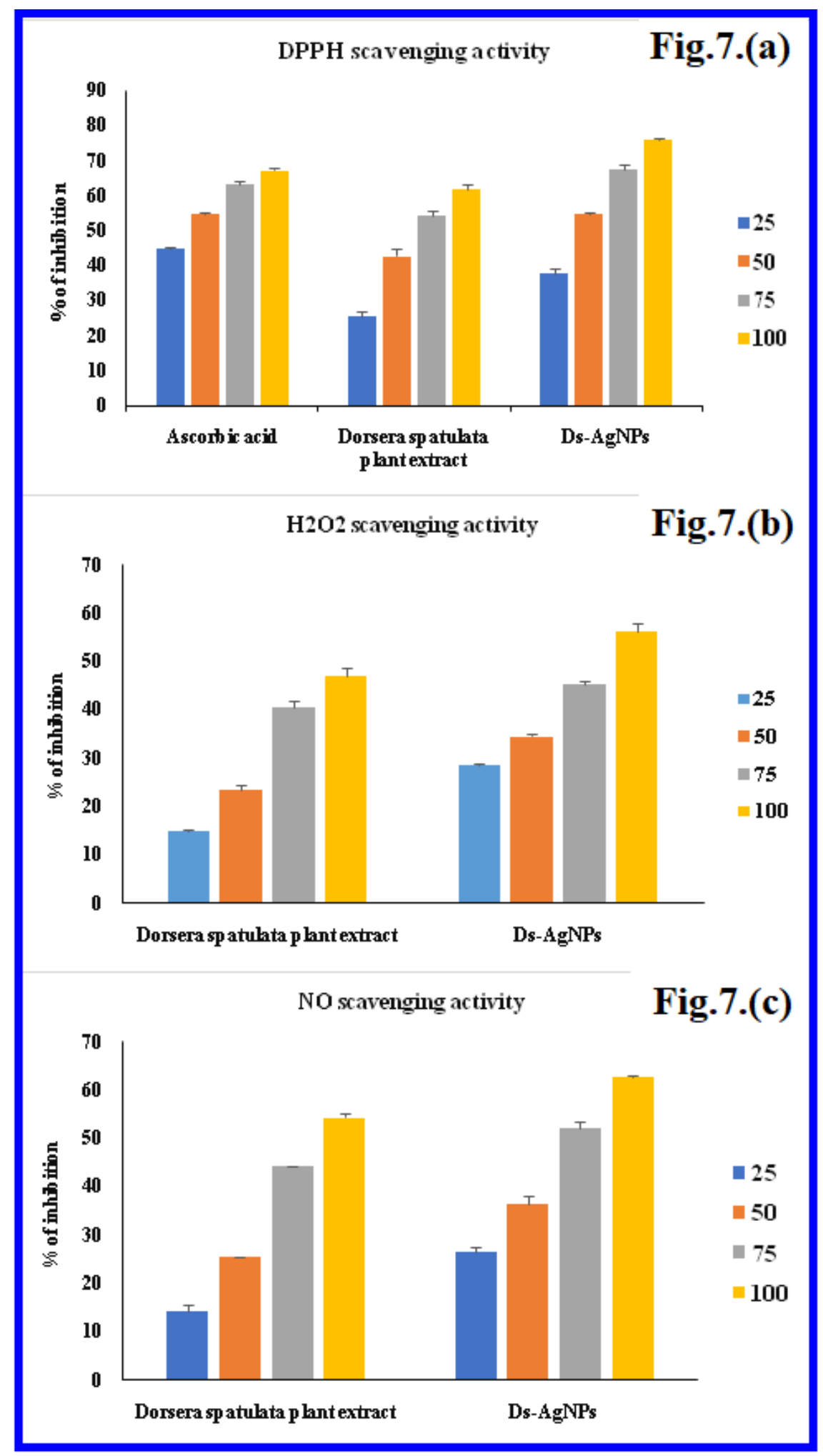

Figure 7

(a)DPPH Scavenging activity (b) H2O2 Scavenging activity (c)NO Scavenging activity of biosynthesized Ds-AgNPs 


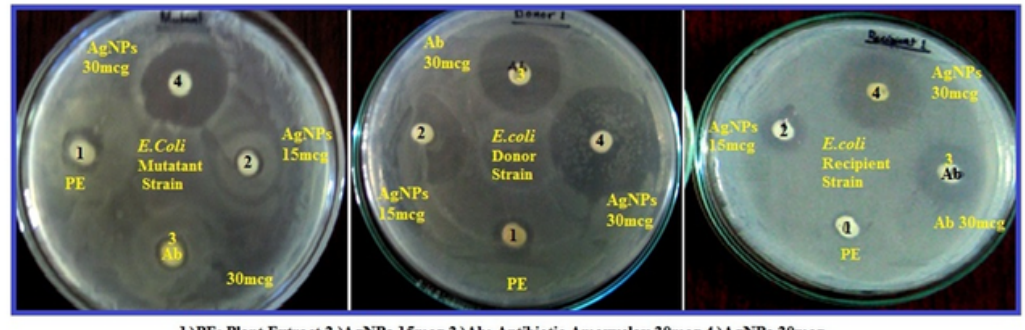

1)PE: Plant Extract 2.)AgNPs $15 \mathrm{mcg} 3$ 3.)Ab: Antibiotic Amoxyclav 30mcg 4.)AgNPs 30mcg
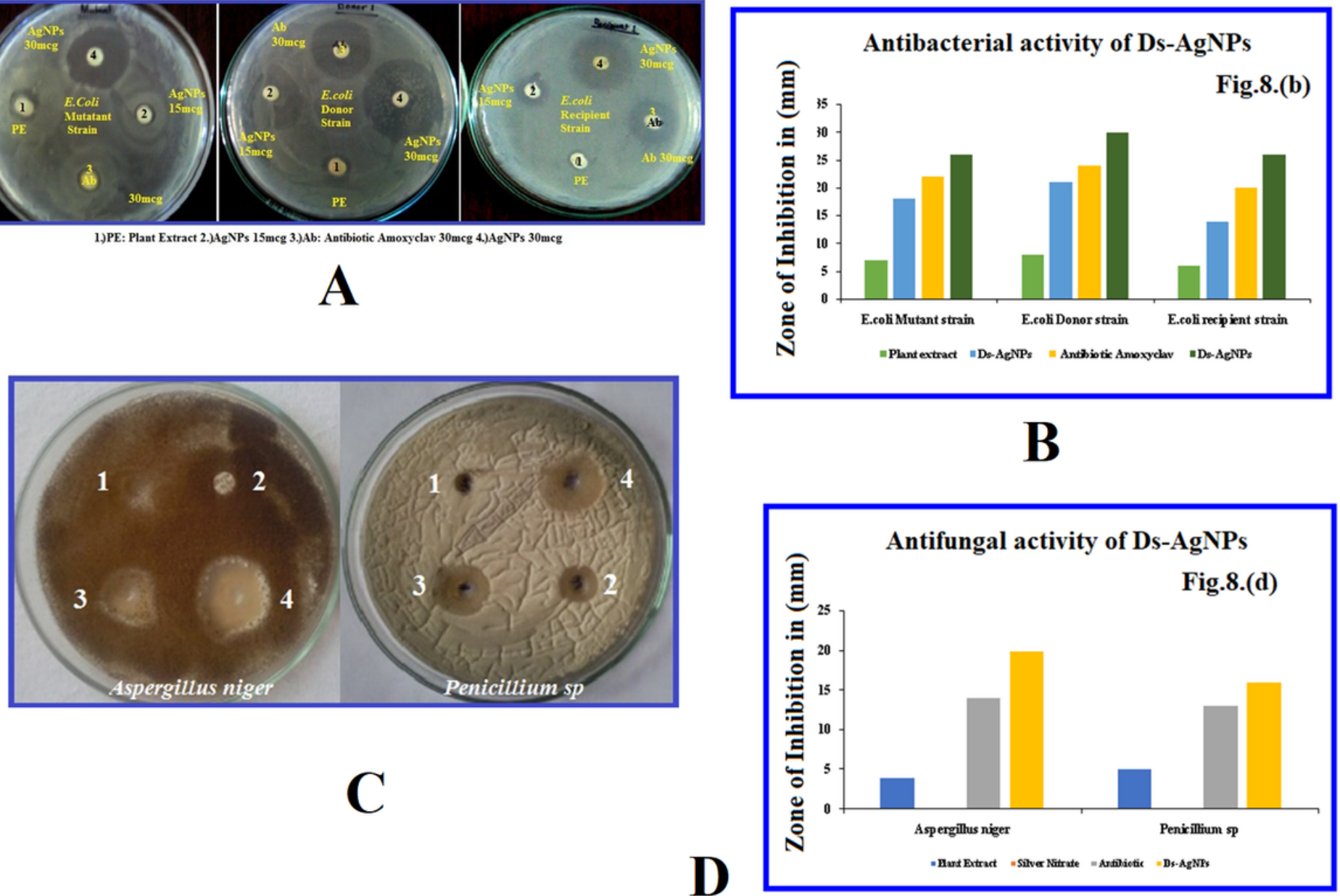

Figure 8

(a). Antibacterial activity of AgNPs on Gram negative antibiotic resistant E.coli strains E.coli Mutant strain, E.coli Donor strain, E.coli recipient strain (b). Graphical analysis of Antibacterial activity of DsAgNPs on Gram negative antibiotic resistant E.coli strains E.coli Mutant strain, E.coli Donor strain, E.coli recipient strain (c). Antifungal activity of AgNPs on Aspergillus niger and Penicillium sp Aspergillus niger: 1. Plant Extract 2. Silver nitrate 3. Nystatin antibiotic (25mcg) 4.Ds-AgNPs Penicillium sp: 1. Silver nitrate 2. Plant Extract 3. Nystatin antibiotic (25mcg) 4. Ds-AgNPs (d). Graphical representation of Antifungal activity of Ds-AgNPs on Aspergillus niger and Penicillium sp 

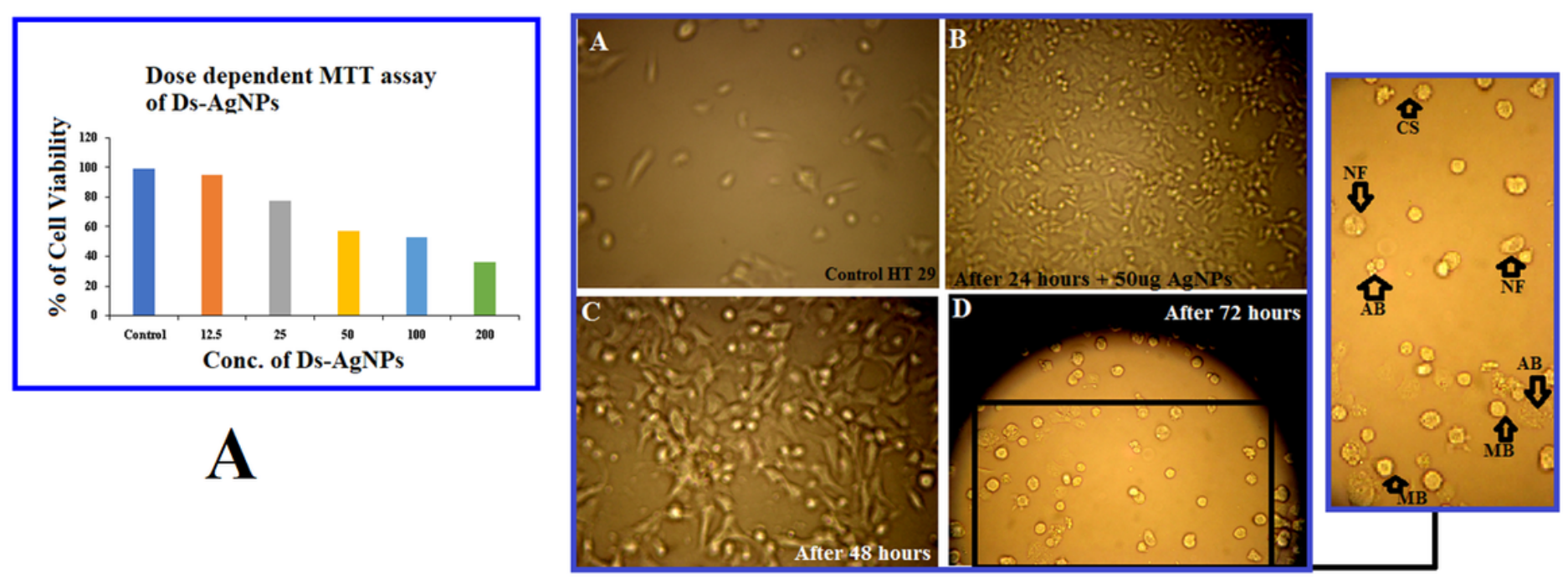

B

Figure 9

(a) Dose dependent Cytotoxic effect of Ds-AgNPs on HT-29 human colon cancer cell by MTT assay (b). Cytotoxic effect of AgNPs on HT-29 human colon cancer cells and its Morphological changes of HT-29 cells observed under an inverted light microscope. A. Untreated HT-29 cells B. HT-29 cells tOreated with 50ug of AgNPs after 24 hours C. HT-29 cells treated with 50ug of AgNPs after 48 hours D. HT-29 cells treated with 50ug of AgNPs after 72 hours. After 72 hours the cells showed distinctive characteristics of apoptosis, such as apoptotic bodies (AB), cellular shrinkage (CS), nuclear compaction (NC), membrane blebbing (MB), and nuclear fragmentation (NF) (magnification 100x).

\section{Supplementary Files}

This is a list of supplementary files associated with this preprint. Click to download.

- S1.png

- S2.png

- S3.png

- googlemap.png 